\title{
Lateral variations of effective elastic thickness of the subducting Philippine Sea plate along the Nankai trough
}

\author{
Shoichi Yoshioka ${ }^{1}$ and Yoshihiro Ito ${ }^{2}$ \\ ${ }^{1}$ Department of Earth and Planetary Sciences, Faculty of Sciences, Kyushu University, Hakozaki 6-10-1, Higashi-ward, Fukuoka 812-8581, Japan \\ ${ }^{2}$ Minamidai 4-50-10-201, Nakano-ku, Tokyo 164-0014, Japan
}

(Received July 2, 1999; Revised September 6, 2000; Accepted September 19, 2000)

\begin{abstract}
We investigated lateral variations of effective elastic thickness of the subducting Philippine Sea plate along the Nankai trough. For this purpose, we applied two-dimensional thin elastic plate bending theory to several profiles almost perpendicular to the trough axis, correcting the effect of thick marine sediments in the Shikoku Basin. The 15 topographic profiles were selected from 61 profiles and were fit to respective theoretical deflection curves by minimization of the $L_{1}$ norm. Classifying the Shikoku Basin into three regions, namely, the western, the middle, and the eastern regions, we obtained the results that the effective elastic plate thickness tends to decrease gradually from the east of the Ryukyu-Palau ridge to the Kinan seamount chain. This is consistent with heat flow data, seafloor age, formation process of the Shikoku Basin, length of the slab subducted from the Nankai trough, and spatial distribution of subcrustal earthquakes associated with subduction of the Philippine Sea plate.
\end{abstract}

\section{Introduction}

One of the well-known features of island arc-trench system is an Outer Rise or topographic high, which appears of the order of $100 \mathrm{~km}$ seaward of most trench axes. The existence of the Outer Rise in association with an oceanic trench has been explained in terms of the flexure of a thin elastic lithosphere acted upon by horizontal and vertical forces. Several researchers have used the elastic and elastic-plastic plate theory to describe the flexure of the lithosphere in the vicinity of oceanic trenches (e.g., Hanks, 1971; Watts and Talwani, 1974; Caldwell et al., 1976; McAdoo et al., 1978; Bodine and Watts, 1979; Caldwell and Turcotte, 1979; Bodine et al., 1981; Levitt and Sandwell, 1995; Mueller and Phillips, 1995).

In southwest Japan, the oceanic Philippine Sea plate is subducting beneath the continental Eurasian (or Amurian) plate along the Nankai trough. The current plate motion of the Philippine Sea plate relative to the Eurasian plate is estimated to be oriented about $\mathrm{N} 50^{\circ} \mathrm{W}$, and convergence rate is $4.6 \mathrm{~cm} /$ year at the Nankai trough (Seno et al., 1993). The direction is also consistent with the relative plate motion deduced from geodetic data inversion of recent GPS data in southwest Japan (Ito et al., 1999).

On the other hand, recent studies of magnetic anomalies in the Shikoku Basin have revealed processes of tectonic evolution and seafloor age of the basin (e.g., Okino et al., 1994; Kobayashi et al., 1995). The Shikoku Basin is situated in the northern part of the Philippine Sea plate (Fig. 1), and was formed as a backarc basin of the N-S trending Izu-Bonin arc. The NNW-SSE trending Kinan seamount chain, which was

Copy right(C) The Society of Geomagnetism and Earth, Planetary and Space Sciences (SGEPSS); The Seismological Society of Japan; The Volcanological Society of Japan; The Geodetic Society of Japan; The Japanese Society for Planetary Sciences. located near the spreading center, is the youngest region in the basin. The Shikoku Basin is considered to spread in the NE-SW and/or ENE-WSW directions for the period from 30 to $15 \mathrm{Ma}$ (e.g., Kobayashi and Nakada, 1978; Shih, 1980). Therefore, the former ridge (near the Kinan seamount chain) is located almost perpendicular to the Nankai trough, and the plate age becomes old toward the SW or WSW direction away from the Kinan seamount chain, indicating very peculiar place in the frame of the plate tectonics. If we assume that the oceanic plate follows the plate cooling model, we can expect the plate becomes thicker from the Kinan seamount chain toward the Kyushu-Palau ridge along the Nankai trough. Such lateral variations of the plate thickness along the trough axis might be detectable if we use large amount of data and appropriate analytical method. For this purpose, we used topography corrected thickness of marine sediments in the Shikoku Basin, and applied the thin elastic plate bending theory to the data.

Researches on lateral variations of the plate thickness along the Nankai trough have not been done so far. Although it is well known that the Shikoku Basin is covered with thick marine sediments, there has been no reliable data of their spatial distribution. This has been a very serious problem when we delineate correct topography to estimate effective elastic plate thickness. In some cases the shape of the Outer Rise was considerably altered by removing the sediments from the observed bathymetry profiles. Although Caldwell and Turcotte (1979) estimated effective elastic plate thickness at the Nankai trough to be less than $20 \mathrm{~km}$, correction for the thick marine sediments was not done in their research, causing erroneous estimation of the elastic plate thickness We overcame this problem, using up-to-date data of distribution of marine sediments in the Shikoku Basin compiled by Nemoto et al. (1995). Real topography is occasionally far 


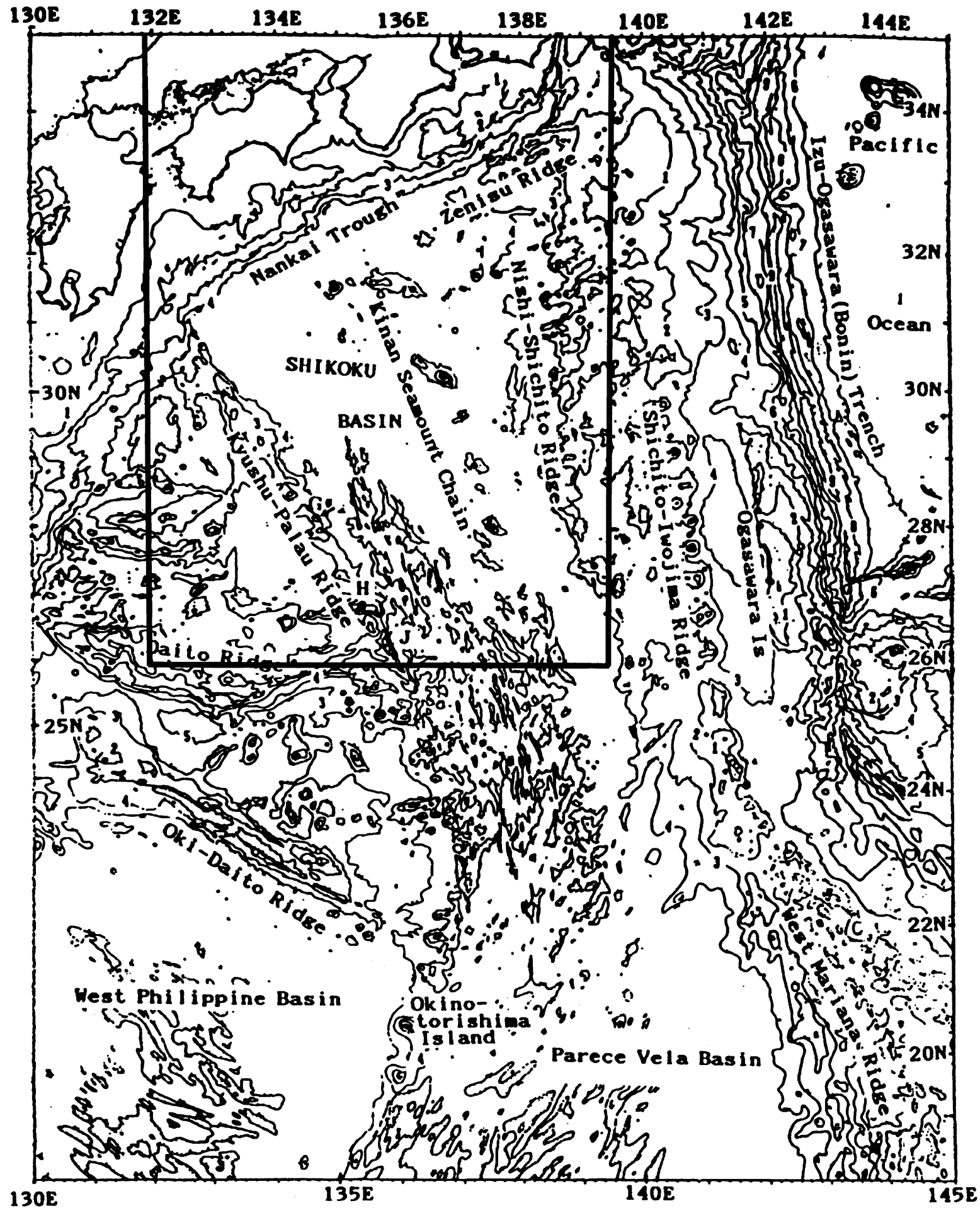

Fig. 1. Location map in and around the Shikoku Basin (modified from Kobayashi et al., 1995). The contour interval is $1 \mathrm{~km}$. The boxed region $\left(131.9^{\circ} \mathrm{E}-139.5^{\circ} \mathrm{E}, 26.0^{\circ} \mathrm{N}-35.4^{\circ} \mathrm{N}\right)$ is the investigated area in this study.

from theoretical curves due to existence of local topographic highs. Therefore, to obtain better and objective fitting curve, we solved the problem by minimizing the $L_{1}$ norm.

2. Spatial Distributions of Bathymetry and Marine Sediments in the Shikoku Basin

Figure 2(a) shows the location of bathymetric data for the area of $131.9^{\circ} \mathrm{E}-139.5^{\circ} \mathrm{E}, 26.0^{\circ} \mathrm{N}-35.4^{\circ} \mathrm{N}$ in and around the
Shikoku Basin, whose data were provided by Hydrographic Department, Maritime Safety Agency of Japan. Total number of data reaches almost 130,000 points. The data are satisfactory enough to delineate profiles of topography of the Shikoku Basin.

Figure 2(b) represents observation points of thickness of marine sediment, which were provided by Nemoto et al. (1995). They used velocity gradient models from sonobuoy 
Table 1. Parameters used in calculation.

\begin{tabular}{cccc}
\hline Parameter & Assumed value & Meaning of the parameter & Unit \\
\hline$E$ & $6.5 \times 10^{10}$ & Young's modulus & $\mathrm{N} / \mathrm{m}^{2}$ \\
$k\left(=g\left(\rho_{m}-\rho_{w}\right)\right)$ & $2.4 \times 10^{3}$ & resistance to vertical loading & $\mathrm{kg} / \mathrm{m}^{2} \cdot \mathrm{s}^{2}$ \\
$v$ & 0.25 & Poisson's ratio & \\
$D\left(=E H^{3} / 12\left(1-v^{2}\right)\right)$ & & flexural rigidity & $\mathrm{N} \cdot \mathrm{m}$ \\
\hline
\end{tabular}

travel-time and an equation in order to convert observed twoway travel times into thickness of sediments (Ludwig and Houtz, 1979). The reliability of the thickness was verified by comparing the model with measured velocity of samples from DSDP and ODP. Since total number of the data is less than 10,000 , the distribution is relatively sparse as compared with the bathymetric data. Although there appears to be a region where no data were available along the continental slope just north of the Nankai trough. However, since we only use data of bathymetry and sediment thickness seaward of the trough axis, the region with no data does not affect our results at all.

To evaluate the data of bathymetry and thickness of marine sediments at the same points, we constructed 50,688 $(192 \times 264)$ grid points with interval of $4 \mathrm{~km}$ in the directions of latitude and longitude. Since length for the same degree along the latitude become longer toward the south, we corrected the effect when we convert the data given in longitude and latitude into the grid points in $\mathrm{km}$. For the bathymetric data, in order to produce depths at all the grid points, we searched several data close to a target point, and take average of them with weight proportional to the inverse of a distance from the point (Fig. 3(a)). In the southern part of the Shikoku Basin, the depth reaches 4000 to $5500 \mathrm{~m}$, and becomes shallow gently toward the Nishi-Shichito ridge in the east. The topography is relatively complicated in the southern region, while there are some regions with flat seafloor in the north in the Shikoku Basin.

On the other hand, as to the thickness data of marine sediments, there are not enough data to obtain their spatial distribution. Therefore, we carried out smoothing for the data, using bi-cubic B-spline function. In order to obtain optimal smoothness, we used a criterion to minimize Akaike's Bayesian Information Criterion (ABIC), proposed by Akaike (1980) on the basis of the entropy maximization principle (Akaike, 1977). We show in Fig. 3(b) thus obtained distribution of thickness of marine sediments. The thickness gradually decreases toward the south in the Shikoku Basin, being consistent with gradual southwestward increase of Bouguer gravity anomalies (Kobayashi et al., 1995). The landward slope just north of the Nankai trough is currently compressional due to subduction, and much of the sedimentary section is deformed and accreted to the upper wedge as the accretionary prism. This consists mainly of offscraped and underplated materials from trough fill turbidites and the Shikoku Basin hemipelagic sediments (Ashi and Taira, 1992). Along the Nankai trough, we find elongated thick marine sediments. Sediment thickness reaching almost $1800 \mathrm{~m}$ is found along the trough, whose sediments are originated from land, being transported from the east along the trough. Supply of sedi- ment was presumably reduced or eliminated associated with Pliocene development of the Nankai trough (Karig, 1975; White et al., 1980). The thick sediment along the Nankai trough indicates that correction for the marine sediments must be done to estimate accurate effective elastic plate thickness there.

Since the data of bathymetry and thickness of marine sediments were obtained at the same 50,688 points, we can obtain net depth to the surface of the subducting Philippine Sea plate from the sea level. For this purpose, we first considered the effect of rebound of the plate associated with removal of the marine sediments. Assuming that isostasy is hold, the amount of rebound of the plate, $h_{x}$, can be given by

$$
h_{x}=\frac{\rho_{s}-\rho_{w}}{\rho_{m}-\rho_{w}} h_{s}
$$

where $h_{s}$ is the thickness of sediment at each point, and $\rho_{S}$, $\rho_{w}$, and $\rho_{m}$ are densities of sediment, water, and the uppermost mantle, respectively. Here, we substituted the values of $\rho_{s}=1700 \mathrm{~kg} / \mathrm{m}^{3}$ (Nishizawa and Suyehiro, 1986), $\rho_{w}=1000 \mathrm{~kg} / \mathrm{m}^{3}$, and $\rho_{m}=3400 \mathrm{~kg} / \mathrm{m}^{3}$ into Eq. (1) to obtain correction of rebound $h_{x}$ at each point. Figure 3(c) is obtained depth to the surface of the Philippine Sea plate, using the two data set and the correction of rebound $h_{x}$ at the corresponding grid points $(4 \mathrm{~km}$ mesh). From east to west, the Nishi-Shichito ridge, the Kinan seamount chain, and the Kyushu-Palau ridge are delineated clearly as continuous topographic highs. In the deepest portion of the Nankai trough, the depth reaches more than $5900 \mathrm{~m}$, and continental slope is very sharp just north of the trough axis. From Fig. 3(c), we find that relatively flat region exists just northeast of the Kyushu-Palau ridge. Using the data of Fig. 3(c), we produced profiles perpendicular to the trough axis, and attempted to estimate effective elastic plate thickness for each profile, using the thin elastic bending theory, which will be described in detail in the next section.

\section{Simple Elastic Flexture Model}

In this study, we employed the elastic plate model (e.g., Bodine and Watts, 1979) to investigate the corrected data for the thickness of marine sediments. Although elastic-plastic model is said to be better for curve fitting, when we take into account the plastic deformation, we need data such as temperature distribution at the trough and yield stress, and have to determine the range of the state of flexture of the slab. Normally, for the elastic-plastic model, the slab is divided into four regions: the region of only elastic deformation (region I), plastic yielding in the lower side of the slab (region IIA), plastic yielding on both sides of the slab with an elastic core in between (region IIB), and plate begins to 
(a)

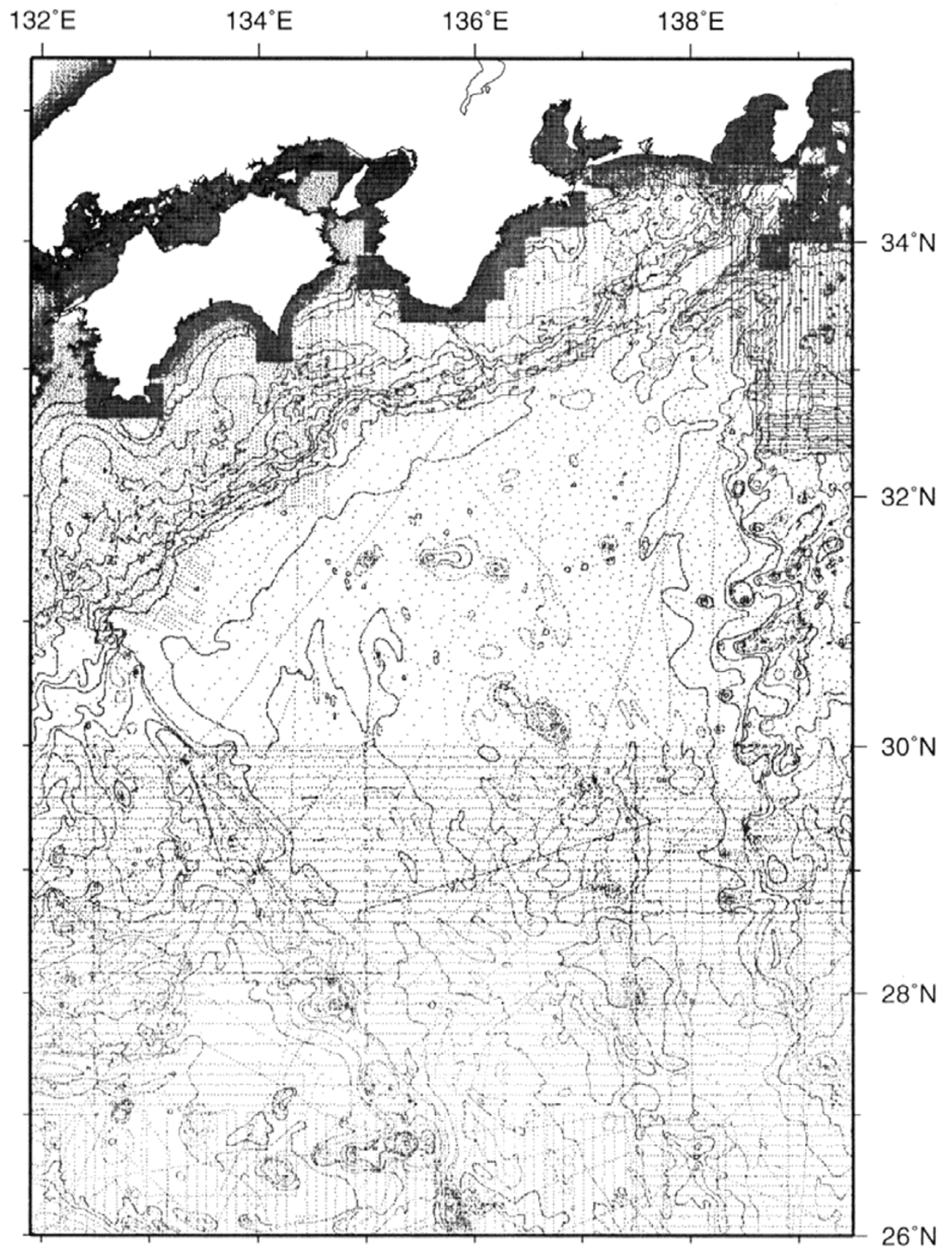

Fig. 2. Spatial distribution for which marine data were observed in and around the Shikoku Basin. (a) Points for which bathymetry data were obtained by Hydrografic Department, Maritime Safety Agency of Japan. The total number of the data is about 130,000. (b) Points for which thickness of marine sediments were compiled by Nemoto et al. (1995). The total number of the data is less than 10,000. The thick barbed line denotes the location of the Nankai trough.

unbend and all plastic yielding (region III) (e.g., Bodine and Watts, 1979). Therefore, since parameters which should be given increase in this model, it would be difficult to constrain lithospheric thickness and its feature. Bodine et al. (1981) also concluded that considerations of rheology of an oceanic lithosphere suggest that the simple elastic model is adequate for approximating lithospheric flexture. For these reasons, we used the thin elastic plate model in this study. However, we will mention limitation of applicability of the elastic bending model in the later section.

Following Bodine and Watts (1979), we briefly describe the model. The model is two-dimensional in a vertical cross section, and $x$-axis is taken along a topographic profile almost perpendicular to the trough axis. The plate is acted upon by a restoring force $k w$, which is given by $g w\left(\rho_{m}-\rho_{w}\right)$, where $k$ is resistance to vertical loading, $w$ is the deflection, $g$ is average gravity, and $\rho_{m}$ and $\rho_{w}$ are density of the uppermost mantle $\left(3400 \mathrm{~kg} / \mathrm{m}^{3}\right)$ and water $\left(1000 \mathrm{~kg} / \mathrm{m}^{3}\right)$, respectively. 
(b)

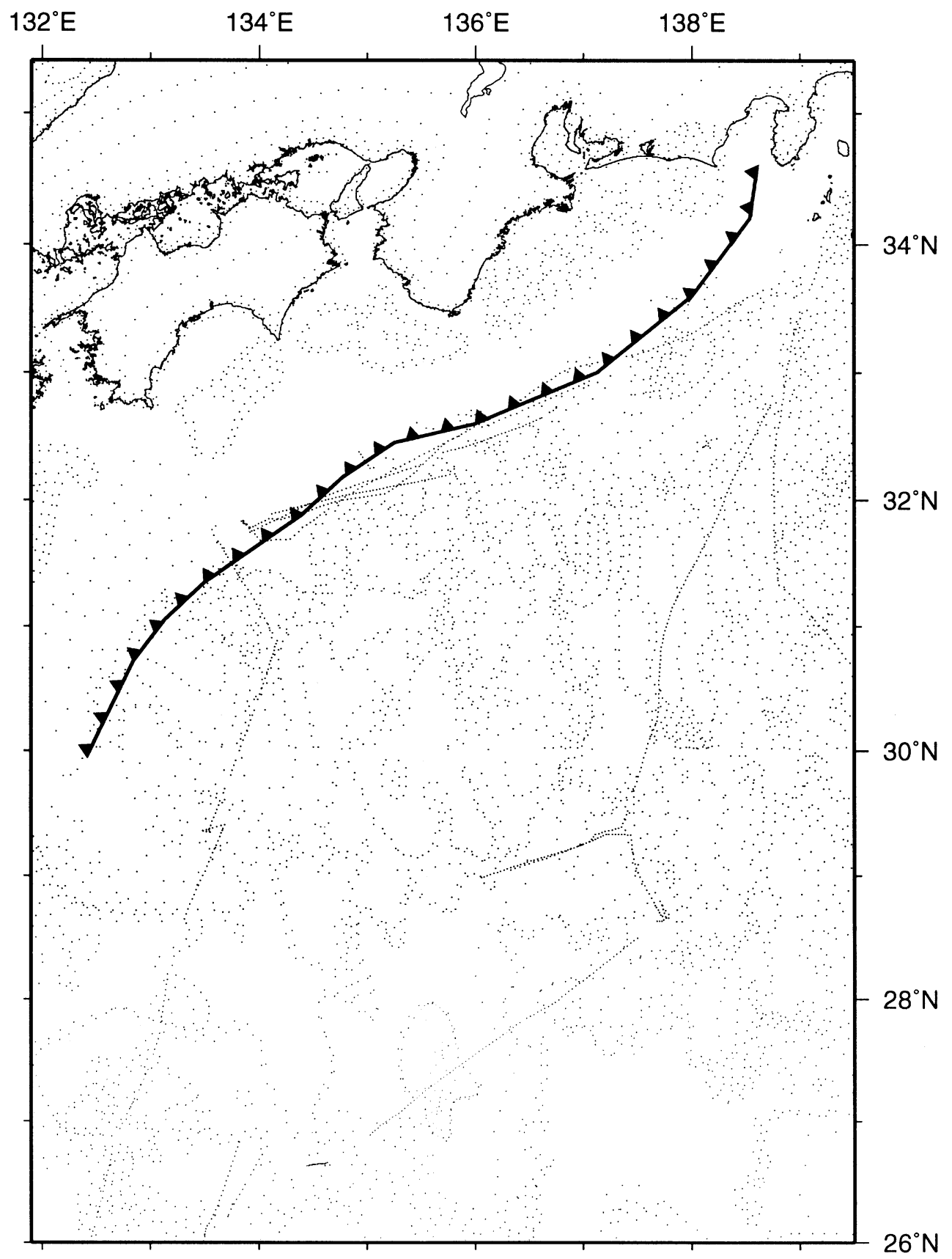

Fig. 2. (continued).

If the applied loads comprise a horizontal force $T$, a vertical force $Q$, and a bending moment $M$, the equilibrium equations are given by

$$
\begin{aligned}
& \frac{d T}{d x}=0 \\
& \frac{d Q}{d x}=-k w \\
& \frac{d M}{d x}=-T \frac{d w}{d x}-Q .
\end{aligned}
$$

The relationship between the curvature of the plate and the bending moment is given by

$$
M=-D \frac{d^{2} w}{d x^{2}}
$$

where $D$ is the flexural rigidity of the elastic plate (Table 1 ). Combining equations (2) to (5), we obtain

$$
D \frac{d^{4} w}{d x^{4}}-T \frac{d^{2} w}{d x^{2}}+k w=0
$$

Solving equation (6) for boundary conditions $w=0$ at $x=$ 0 , and $w=0$ at $x=\infty$, the deflection $w$ is given by the 


\section{(a)}

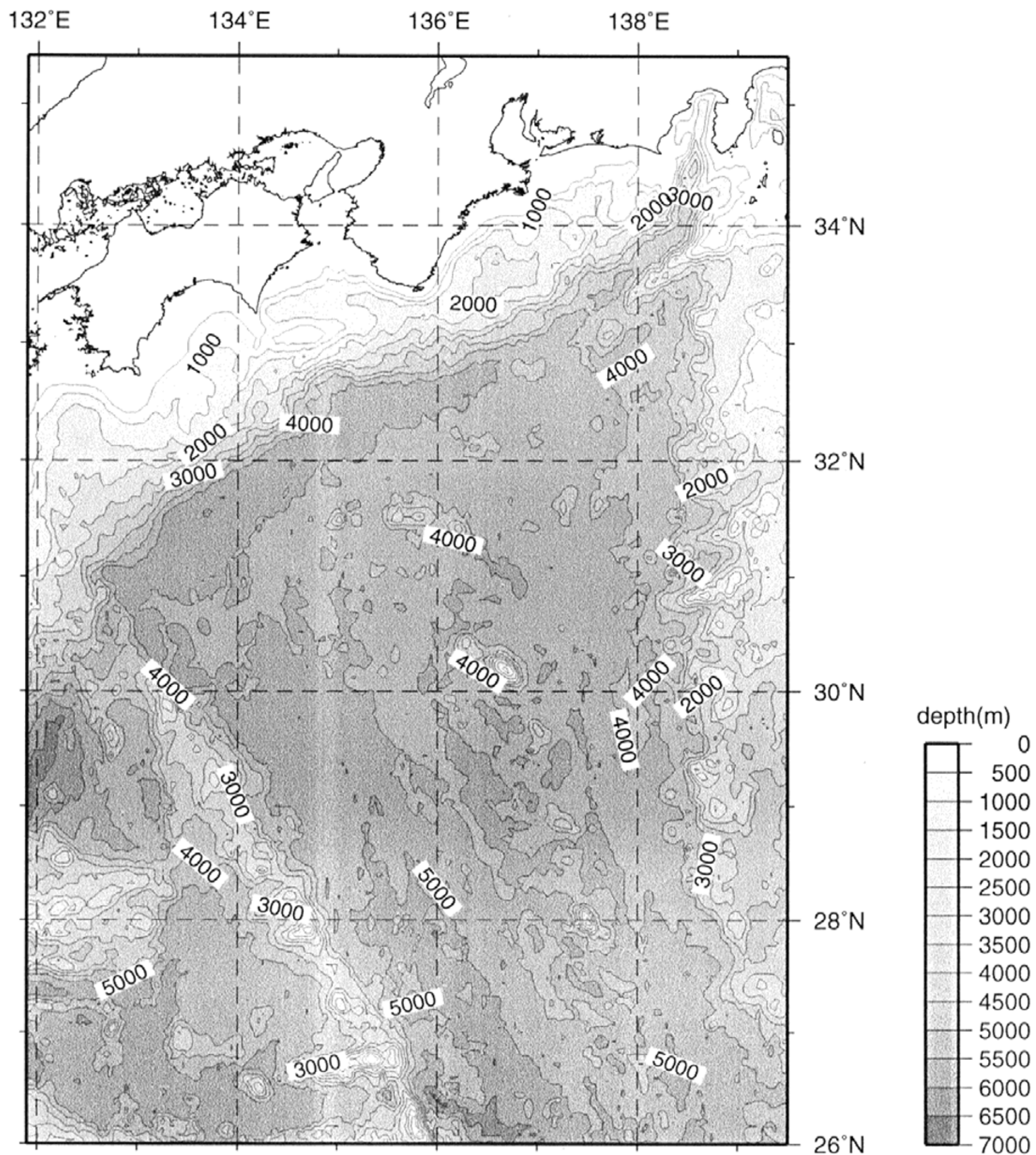

Fig. 3. (a) Contour map of bathymetry in and around the Shikoku Basin obtained from data of Fig. 2(a). The contour interval is $500 \mathrm{~m}$. (b) Contour map of thickness of marine sediments in and around the Shikoku Basin obtained from data of Fig. 2(b). The contour interval is $500 \mathrm{~m}$. (c) Contour map of depths to the upper surface of the Philippine Sea plate measured from the sea level. The data are obtained, by adding data of Fig. 3(b) to those of Fig. 3(a), after making correction of rebound of the plate associated with removal of marine sediments. The contour interval is $500 \mathrm{~m}$.

following form:

$$
w=w_{0} \sin \left(\frac{x}{\alpha}(1+\epsilon)^{\frac{1}{2}}\right) \exp \left(-\frac{x}{\alpha}(1-\epsilon)^{\frac{1}{2}}\right)
$$

where $w_{0}$ is deflection at the left end of $x$-axis, $\alpha=(4 D / k)^{\frac{1}{4}}$, and $\epsilon=-T /(4 k D)^{\frac{1}{2}}$. Since two solutions are trivial, two boundary conditions are enough to solve the differential equation (6). The parameter $\epsilon$ is dependent on the magnitude of the horizontal loading $T$ and is proportional to the inverse square root of Young's modulus, $E$. The value of $\epsilon$ is small
( $\sim 0.1$ ) for the values of horizontal loading considered in this study and for variations in Young's modulus. Thus $\epsilon$ may be neglected in the elastic model (Caldwell et al., 1976). In this case, using location $\left(x_{b}, w_{b}\right)$ of an Outer Rise, the deflection $w$ is given by

$$
w=w_{b} \sqrt{2} \exp \left(\frac{\pi}{4}\right) \sin \left(\frac{x \pi}{4 x_{b}}\right) \exp \left(\frac{-x \pi}{4 x_{b}}\right) .
$$

Here, $x_{b}$ is related to the effective elastic plate thickness $H$, 
(b)

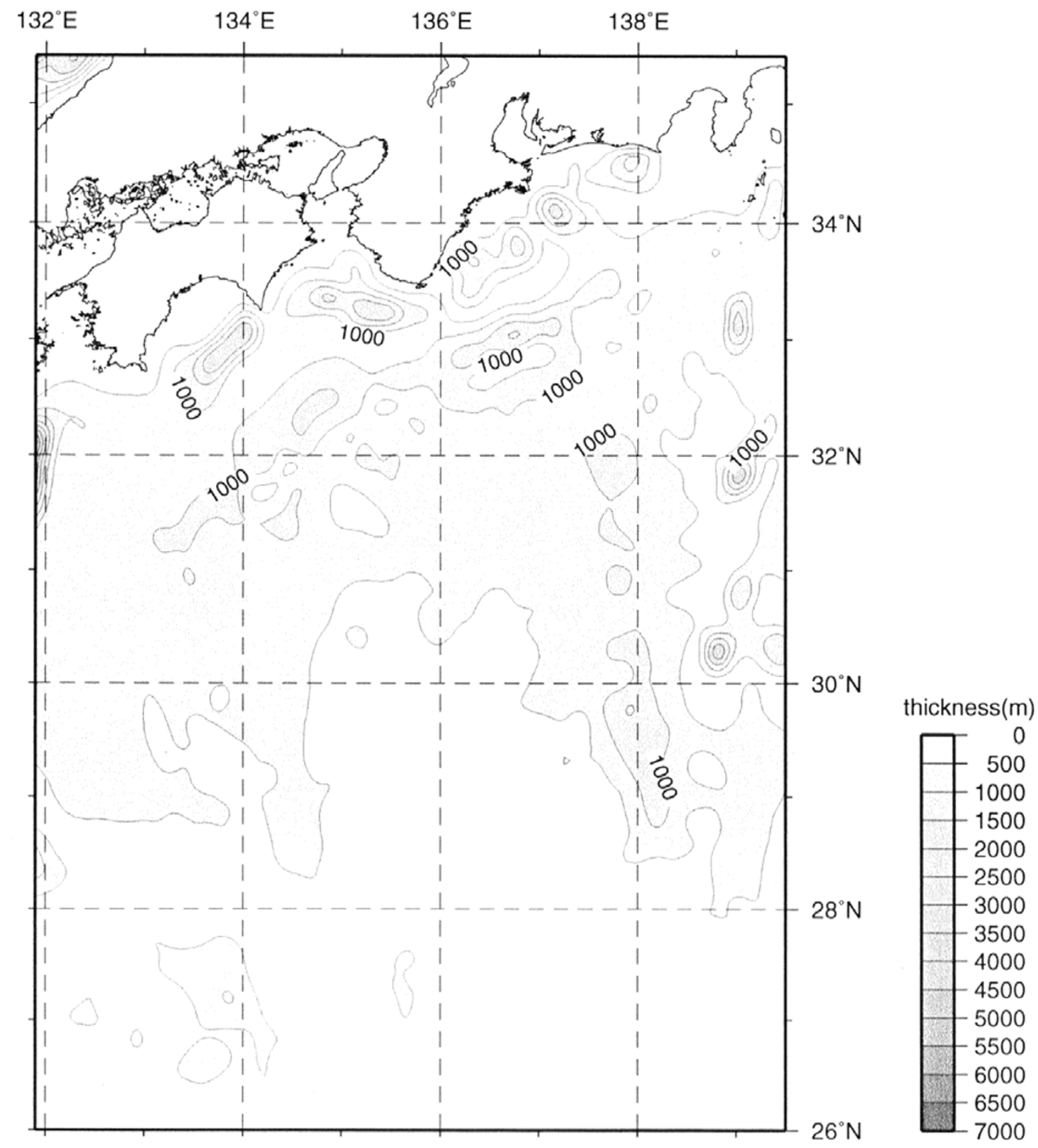

Fig. 3. (continued).

and Poisson's ratio $v$, by

$$
x_{b}=\frac{\pi}{4}\left(\frac{E H^{3}}{3 k\left(1-v^{2}\right)}\right)^{\frac{1}{4}} .
$$

Once $x_{b}$ is determined, we can obtain elastic plate thickness from Eq. (9). Substituting Eq. (8) into Eq. (5), we can derive bending moment $M$ analytically as a function of $x$, and thus maximum bending moment $M_{\max }$. Maximum tensile stress in the $x$ direction $\sigma_{\max }$ can be calculated following De Bremaecker (1977),

$$
\sigma_{\max }=\frac{M_{\max } H}{2 \times \frac{H^{3}}{12}}=\frac{6 M_{\max }}{H^{2}} .
$$

In this study, we did not take into account the effect of stresses in the along-strike direction, including sphericity. However, recent analytical study of spherical shell by Tanimoto (1997, 1998) demonstrated that Earth's lithospheric deformation (displacement) can be well approximated by a flat-plate deformation, and sphericity is not important for vertical displacement because of the dominance of the buoyancy force (gravitational effects), though bending stress and compressive stress along the trench axis depends strongly on the effect of sphericity. Since we are only focusing on deformation, the effect of sphericity could be neglected. 
(c)

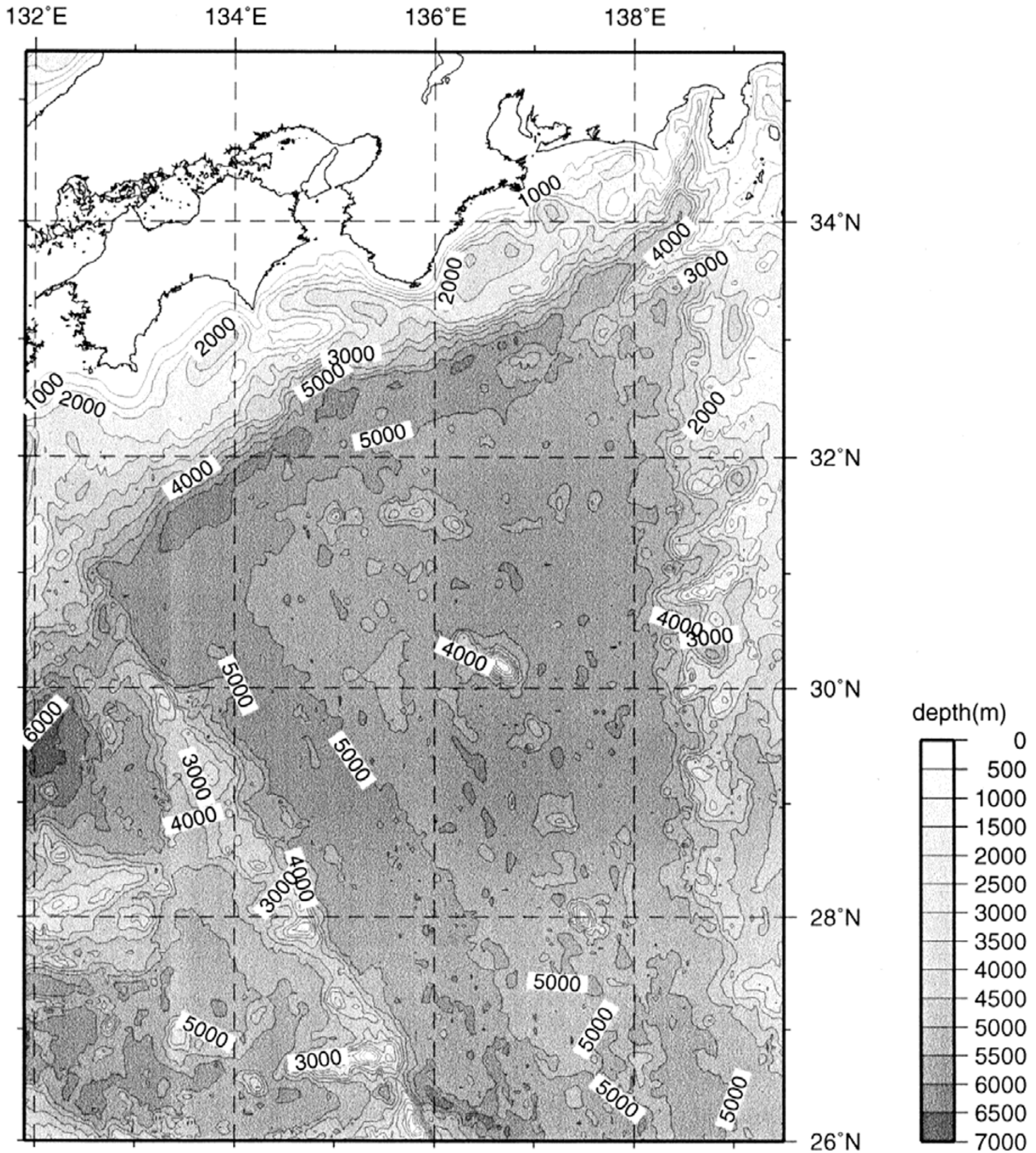

Fig. 3. (continued).

\section{Results}

\subsection{Effective elastic plate thickness along profiles per-} pendicular to the Nankai trough

In this section, we first produce 61 profiles with each length of $500 \mathrm{~km}$ with the same interval of $9.85 \mathrm{~km}$ almost perpendicular to the trough axis $\left(\mathrm{N} 27^{\circ} \mathrm{W}\right)$, using the data of Fig. 3(c). This direction is also close to that of the magnetic anomalies, which have been found on the seafloor in the Shikoku Basin, as will be described in the later section. Among from the 61 observed profiles, we excluded 46 profiles which are difficult for smooth curve fitting because of the existence of some seamounts and/or complicated topography. As a result, we compared 15 observed profiles with theoretical curves (Fig. 4). Since plate thickness appears to be related to formation process of the Shikoku Basin, we took the direction of $\mathrm{N} 27^{\circ} \mathrm{W}$, instead of that of current plate motion $\mathrm{N} 50^{\circ} \mathrm{W}$ (Seno et al., 1993).

We attempted to fit a theoretical curve (dashed line) to an observed profile (solid line) to obtain effective elastic plate thickness for each profile (Fig. 5). The procedure to determine the best fitting curve is as follows: First, we determined the range of data fitting along each profile. Here, the variable parameters are $x_{b}, w_{b}$, and locations of $x$ - and $w$-axes, which were determined by minimizing the $L_{1}$ norm. Since 


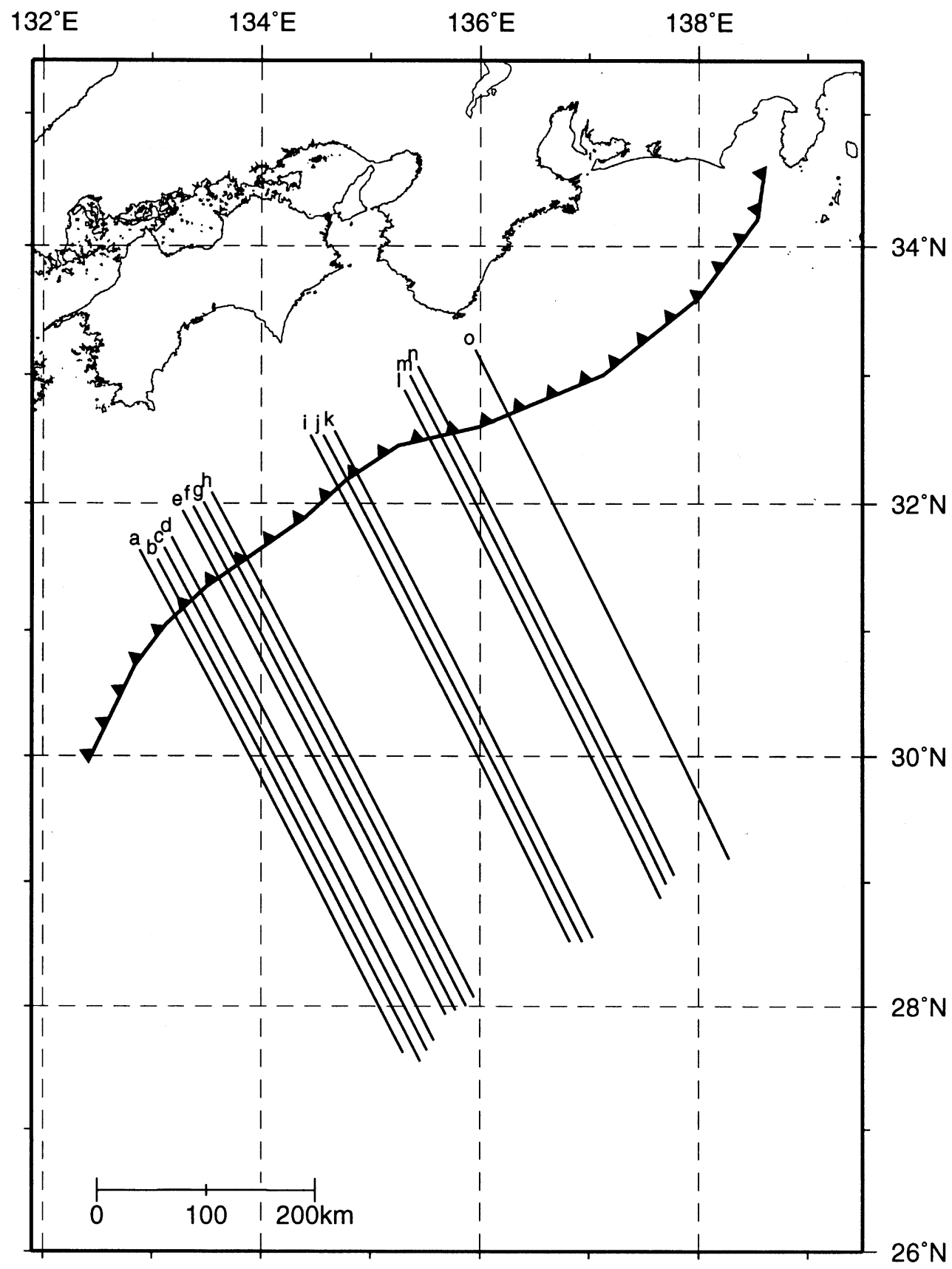

Fig. 4. The investigated 15 profiles almost perpendicular to the Nankai trough $\left(\mathrm{N} 27^{\circ} \mathrm{W}\right)$ among from equidistance 61 profiles. The length of each profile is $500 \mathrm{~km}$. The profiles with alphabet (a) to (o) are shown in Fig. 5. The thick barbed line denotes the location of the Nankai trough.

$x_{b}$ is sensitive to the location of $w$-axis and the range of data fitting, we carefully selected the values of these parameters among from many possible values, and obtained the four parameters. However, we excluded the case when the adjacent profiles are quite different in the locations of $x$ - and $w$-axes.

Here, we classified the 15 profiles into three regions: the western, the middle, and the eastern regions. The profiles in the western region are characterized by smooth topography and gentle curvature (Figs. 5(a)-(h)). At the western end, the height of the Outer Rise is low, and gradually increases toward the northeast in the western region. As can be found in Eq. (9), the longer the length of $x_{b}$ becomes, the thicker the effective elastic plate thickness is. In the western region, since the length of $x_{b}$ is relatively long, the elastic plate can be estimated to be relatively thick.

In the middle region, since topographies are not so smooth due to the existence of some seamounts, curve fitting becomes difficult (Figs. 5(i)-(k)). However, we can find that the lengths of $x_{b}$ in this region become shorter than those in the western region, indicating thinner elastic plate in the middle region.

For the profiles in the eastern region, curve fitting becomes more difficult because of complicated topography with short wavelength (Figs. 5(1)-(o)). The curvatures of the theoretical curves appear to be similar to those in the middle region. However, the lengths of $x_{b}$ are shorter for the profiles in the 


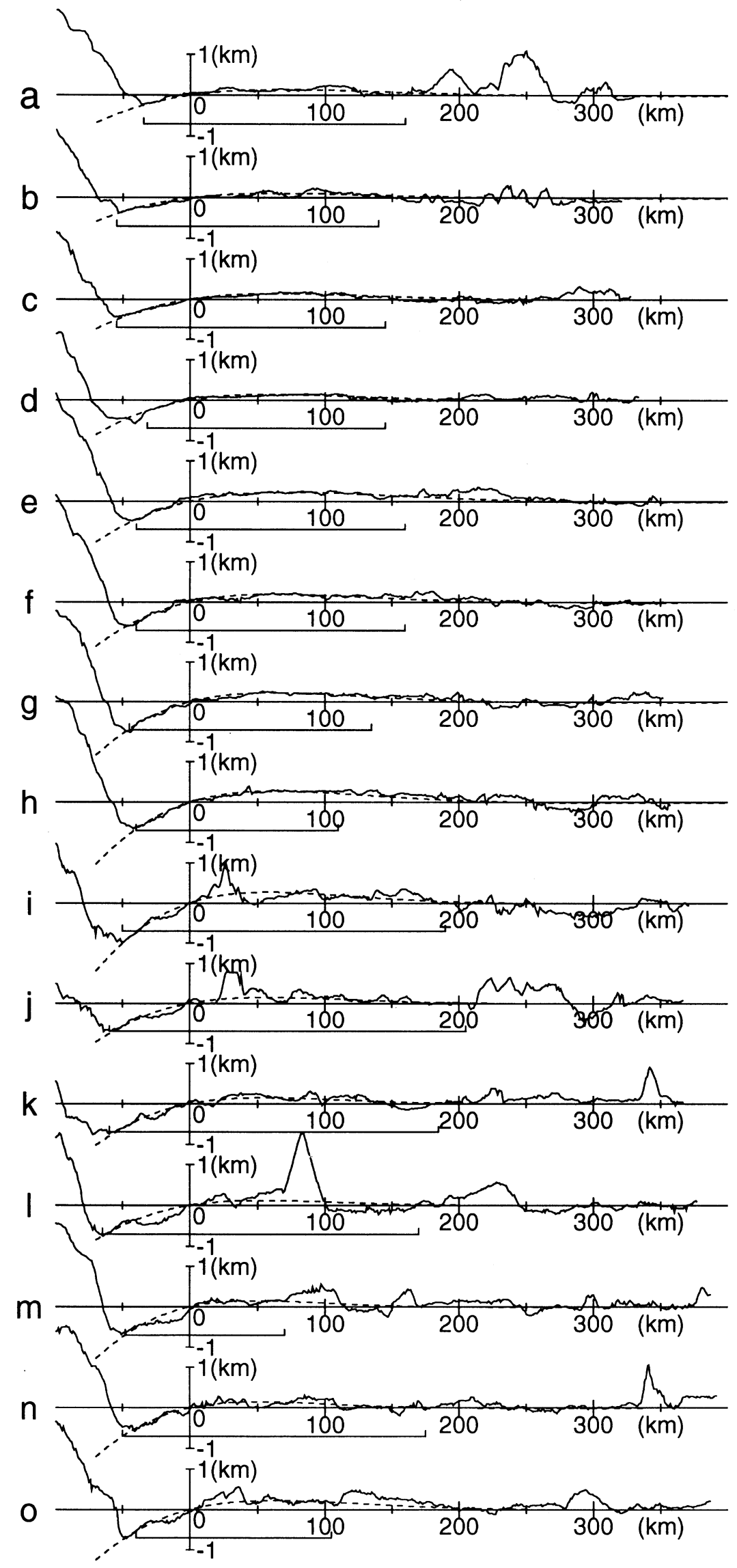

Fig. 5. Profiles for the data of Fig. 3(c). The alphabet (a) to (o) corresponds to the profiles (solid curve) with the same alphabet shown in Fig. 4. The dashed line represents best fitting theoretical curve, which was calculated using equations in Section 3 , for the range in the $x$-axis shown below. The vertical axis $w(\mathrm{~km})$ is exaggerated by 30 times for the horizontal axis $x(\mathrm{~km})$. (a) $\sim(\mathrm{h})$ Profiles in the western region. (i) $(\mathrm{k})$ Profiles in the middle region. (1) (o) Profiles in the eastern region. 


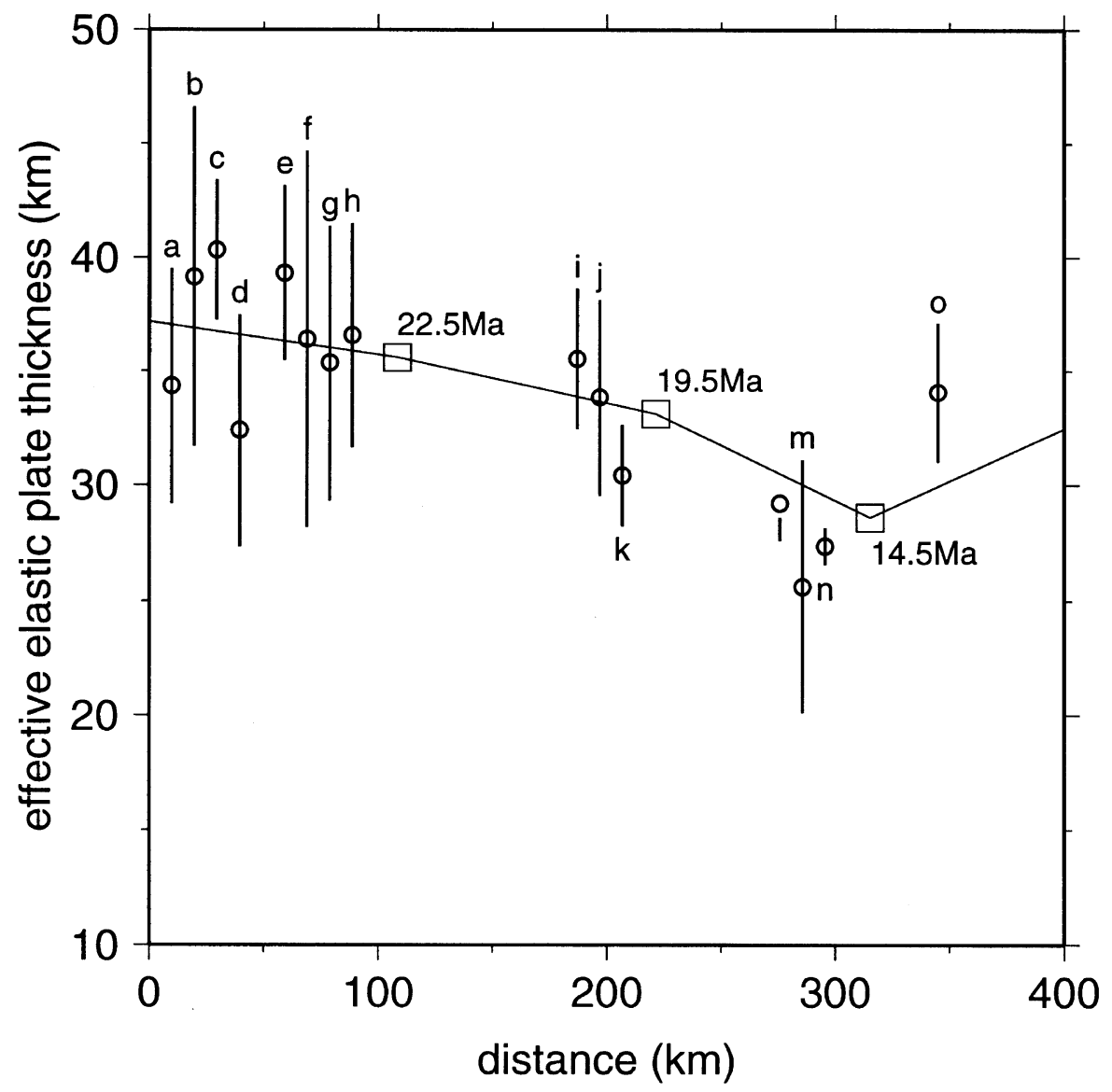

Fig. 6. The values of the effective elastic plate thickness for all the 15 profiles (a) to (o) shown in Fig. 4 . The horizontal axis is the distance perpendicular to the profiles. The vertical bar and open circle for each profile denote standard deviation of the effective elastic plate thickness for three different data sets (given data set and two maximum and minimum data sets, considering observation errors) of bathymetry and thickness of marine sediments. The combination of three data sets are as follows: given bathymetry + given thickness of marine sediments; shallowest bathymetry + thinnest marine sediments; deepest bathymetry + thickest marine sediments. Open squares are locations where seafloor age is assumed from DSDP (Shiono, 1988), and plate thickness estimated from the equation of $7.5 \sqrt{T}$ ( $T$ : seafloor age). Thin solid linear lines are those passing through the points with the open squares.

eastern region than for the middle region.

In summary, the profiles in the western region are gentle and the length of $x_{b}$ are long, indicating thicker effective elastic plate. Toward the middle to the eastern regions, although curve fitting becomes worse due to complicated topography, the curvature becomes steep and the lengths of $x_{b}$ becomes shorter, indicating thinner elastic plate.

Since we obtained the values of $x_{b}$ for each profile, we can estimate lateral variations of the effective elastic plate thickness along the Nankai trough (Fig. 6). From Fig. 6, we can find a tendency that the effective plate thickness becomes thinner from the east of the Kyushu-Palau ridge to the Kinan seamount chain. Its tectonic implication will be discussed in detail in the next section.

Incidentally, we can calculate maximum tensile stress for the 15 profiles, using Eq. (10). Since the value of maximum bending moment $M_{\max }$ obtained from Eqs. (5) and (8) is of the order of $\sim 10^{16} \mathrm{~N}$, the maximum tensile stress in the $x$ direction $\sigma_{\max }$ for the 15 profiles ranges from 210 to 310 $\mathrm{MPa}$. These values may reach yield stress to start plastic deformation. De Bremaecker (1977) also showed that the tensile stress in the case of a viscous plate can be 15 times lower than in the case of an elastic plate. These suggest that the elastic bending model is not appropriate to estimate stresses within a slab, and elastic-plastic, viscous, and viscoelastic (e.g., Sato and Matsu'ura, 1993) models would be more suitable to evaluate the values of stresses there.

\section{Discussion}

\subsection{Estimated plate thickness of the Philippine Sea plate in previous studies}

The thickness of the Philippine Sea plate has been estimated using surface waves and distribution of microearthquakes (e.g., Kanamori and Abe, 1968; Seekins and Teng, 1977; Ishida, 1992; Oda and Senna, 1994; Nakamura and Shibutani, 1998). Although recent results using surface wave indicates regional variation of thickness of the Philippine Sea plate, there is no spatial resolution to reveal lateral variation of the plate thickness along the Nankai trough. The thickness of the Philippine Sea plate was estimated to be about 30 km near the Japanese islands (e.g., Kanamori and Abe, 1968; Ishida, 1992). According to Oda and Senna (1994), the lithospheric thickness estimated from Rayleigh wave dispersion data is about $40 \mathrm{~km}$ in the Shikoku-Parece Vela Basin.

Seismic tomography using $P$ - and $S$-waves has also been conducted to reveal the existence of the subducted Philippine 
Sea plate in southwest Japan (e.g., Hirahara, 1981; Ishida, 1992; Sadeghi, 1999). Using body wave would have better spatial resolution to reveal regional velocity structure as compared to the case for surface waves. However, their results also have not revealed discernible lateral variation of the plate thickness along the Nankai trough. Even in the case of Sadeghi's (1999) up-to-date model, since the grid spacing used in the tomographic reconstruction is half degree in horizontal direction and $15-30 \mathrm{~km}$ in depth, it would be difficult to detect the difference of plate thickness, if any, along the trough axis. Therefore, to reveal lateral variations of the plate thickness along the Nankai trough, our approach using the elastic bending theory would be better in terms of spatial resolution.

\subsection{Lateral variations of the effective elastic plate thick- ness along the Nankai trough and its relation to for- mation process of the Shikoku Basin}

The Shikoku Basin is considered to be formed during the late Oligocene to middle Miocene by two-limbed spreading along the N-S trending central axis as a backarc basin of the previous Izu-Bonin arc associated with subduction of the oceanic Pacific plate. Processes of tectonic evolution of the Shikoku Basin has been discussed by many researchers, mainly using magnetic anomalies (e.g., Tomoda et al., 1968; Kobayashi and Nakada, 1978; Shih, 1980; Seno and Maruyama, 1984; Chamot-Rooke et al., 1987; Okino et al., 1994; Kobayashi et al., 1995). According to Okino et al. (1994), formation of the Shikoku Basin is classified into five successive stages: 1) rifting and formation of unusual dipoles, 2) ENE-WSW spreading (30-23 Ma), 3) E-W spreading (23-19 Ma), 4) NE-SW spreading (19-15 Ma), and 5) widespread off-ridge volcanism and deformation after spreading. At the first stage, they suggested that rifting occurred at the eastern side of the Kyushu-Palau ridge before the opening of the Shikoku Basin, followed by evolution of the Shikoku Basin associated with northwestward motion of the Philippine Sea plate and the eastward trench retreat of the Izu-Bonin-Mariana trench from $30 \mathrm{Ma}$ to $17 \mathrm{Ma}$. At $15 \mathrm{Ma}$, the NE-SW spreading ceased, and the seamounts constructing the Kinan seamount chain are situated in the grabens at the center of the basin. Therefore, the magnetic lineation patterns are almost perpendicular to the Nankai trough, and the plate age becomes young from the east of the Kyushu-Palau ridge (30 Ma) to the Kinan seamount chain (15 Ma). These seafloor ages were also supported from DSDP data (e.g., Shih, 1980; Chamot-Rooke et al., 1987). Chamot-Rooke et al. (1987) also investigated heat flow in the Shikoku Basin. Their results show that the highest heat flow values were found in the youngest area, and the values decreased with increasing age of the plate. Interestingly enough, we can clearly find a tendency that the effective elastic plate thickness becomes thinner from the east of the Kyushu-Palau ridge to the Kinan seamount chain (Fig. 6).

Here, if we apply relationship between plate thickness $h$ (km) and seafloor age $T$ (Ma) (Kono and Yoshii, 1975),

$$
h=7.5 \sqrt{T}
$$

to the thicknesses of the plate below the east of the KyushuPalau ridge to the Kinan seamount chain, the thickness can be thinner from $41 \mathrm{~km}$ to $29 \mathrm{~km}$ toward the northeast. The roughly estimated plate thicknesses agree well with the thicknesses obtained in this study (Fig. 6). These suggest that the effective elastic plate thickness of the Philippine Sea plate along the Nankai trough is strongly dependent on the seafloor age and formation process of the Shikoku Basin.

Furthermore, noticing complicated plate configuration of the subducted Philippine Sea plate (Mizoue, 1977; Mizoue et al., 1983) in southwest Japan, Shiono (1988) investigated relationships among length of the slabs of the Philippine Sea plate after subduction from the Nankai trough, the age of the plate, and seismic activity of subcrustal earthquakes. In general, an oceanic plate which initiates subduction from a trench is cold just after the subduction. As the plate subducts, it would be heated up by the surrounding hot mantle. As time passes, the plate would be assimilated thermally. Some portions which have not been assimilated thermally in a slab are still brittle, causing subcrustal seismic activity. On the other hand, near the leading edge of the slab which has been assimilated thermally, there would be no seismic activity.

Just in the north of the Kinan seamount chain, where the age of the plate is the youngest in the Shikoku Basin, the length of the subducted plate is short and seismic activity of subcrustal earthquakes is limited only beneath southern part of the Kii strait. On the other hand, just in the east of the Kyushu-Palau ridge, where the age of the plate is the oldest, the length of the subducted plate is long and subcrustal earthquakes occur further inland region. From such observations, Shiono (1988) concluded that length of the subducted plate is related to thermal assimilation from the surrounding mantle: thermal assimilation occurs faster for a younger plate than for an older plate, resulting in shorter and longer lengths of the subducted plate, respectively (Shiono and Sugi, 1985). From these results, we suggest that the thickness of the Philippine Sea plate becomes thick as being away from the Kinan seamount chain toward the Kyushu-Palau ridge. Our results of lateral variations of the effective elastic plate thickness along the Nankai trough are consistent with this idea, though our data and the method are completely different from what Shiono (1988) employed.

\section{Conclusions}

We investigated lateral variations of the effective elastic plate thickness of the Philippine Sea plate along the Nankai trough, southwest Japan, applying thin elastic bending theory to the 15 profiles almost perpendicular to the trough axis based on the data of topography, correcting the effect of thick marine sediments in and around the Shikoku Basin.

The effective elastic thickness of the Philippine Sea plate along the Nankai trough tends to decrease from the east of the Kyushu-Palau ridge to the Kinan seamount chain. This seems to be strongly correlated with the processes of tectonic evolution of the Shikoku Basin, which have been estimated from magnetic anomalies and DSDP data. This is also consistent with the length of the Philippine Sea plate subducted from the Nankai trough and spatial distribution of subcrustal earthquakes associated with the subduction.

Acknowledgments. We are indebted to Service Office, Japan Oceanographic Data Center, Hydrographic Department, Maritime Safety Agency of Japan, K. Nemoto, and S. Kasuga for allowing us 
to use data of bathymetry and thickness of marine sediments in and around the Shikoku Basin. T. Yabuki and W. Spakman are gratefully acknowledged for providing source code for smoothing data using ABIC and a graphical software, respectively. We also thank T. Sato, M. Hashimoto, and an anonymous reviewer for their critical review, and K. Okino and J. Ashi for providing us with many useful references. We used CONVEX and SUN S4/2 computer systems at General Information Processing Center of Ehime University.

\section{References}

Akaike, H., On entropy maximization principle, in Application of Statistics, edited by J. M. Krishnaiah, pp. 27-41, North-Holland, Amsterdam, 1977.

Akaike, H., Likelihood and the bayes procedure, in Bayesian Statistics, edited by J. M. Bernardo, M. H. DeGroot, D. V. Lindley, and A. F. M. Smith, pp. 143-166, University Press, Valencia, Spain, 1980.

Ashi, J. and A. Taira, Structure and the Nankai accretionary prism as revealed from IZANAGI sidescan imagery and multichannel seismic reflection profiling, The Island Arc, 1, 103-115, 1992.

Bodine, J. H. and A. B. Watts, On lithospheric flexture seaward of the Bonin and Mariana trenches, Earth Planet. Sci. Lett., 43, 132-148, 1979.

Bodine, J. H., M. S. Steckler, and A. B. Watts, Observations of flexure and the rheology of the oceanic lithosphere, J. Geophys. Res., 86, 3695-3707, 1981.

Caldwell, J. G. and D. L. Turcotte, Dependence of the elastic oceanic lithosphere on age, J. Geophys. Res., 84, 7572-7576, 1979.

Caldwell, J. G., W. F. Haxby, D. E. Karig, and D. L. Turcotte, On the application of a universal elastic trench profile, Earth Planet. Sci. Lett., 31, 239-246, 1976.

Chamot-Rooke, N., V. Renard, and X. LePichon, Magnetic anomalies in the Shikoku Basin: a new interpretation, Earth Planet. Sci. Lett., 83, 214-228, 1987.

De Bremaecker, J. C., Is the oceanic lithosphere elastic or viscous?, J. Geophys. Res., 82, 2001-2004, 1977.

Hanks, T. C., The Kuril trench-Hokkaido rise system: Large shallow earthquakes and simple models of deformation, Geophys. J. R. astr. Soc., 23, 173-189, 1971.

Hirahara, K., Three-dimensional seismic structure beneath southwest Japan: the subducting Philippine Sea plate, Tectonophys., 79, 1-44, 1981.

Ishida, M., Geometry and relative motion of the Philippine Sea plate and Pacific plate beneath the Kanto-Tokai district, Japan, J. Geophys. Res. 97, 489-513, 1992.

Ito, T., S. Yoshioka, and S. Miyazaki, Interplate coupling in southwest Japan deduced from inversion analysis of GPS data, Phys. Earth Planet. Inter., 115, 17-34, 1999.

Kanamori, H. and K. Abe, Deep structure of island arcs as revealed by surface waves, Bull. Earthquake Res. Inst., 46, 1001-1025, 1968.

Karig, D. E., Basin genesis in the Philippine Sea, in Initial Reports of the Deep Sea Drilling Project, 31, pp. 857-879, edited by D. E. Karig, J. C. Ingle, Jr. et al., Washington, 1975.

Kobayashi, K. and M. Nakada, Magnetic anomalies and tectonic evolution of the Shikoku inter-arc basin, J. Phys. Earth, 26, Suppl., S391-S402, 1978.

Kobayashi, K., S. Kasuga, and K. Okino, Shikoku Basin and its margins, in Backarc Basins: Tectonics and Magmatism, edited by B. Taylor, pp. 381405, Plenum Press, New York, 1995.

Kono, Y. and T. Yoshii, Numerical experiments on the thickening plate model, J. Phys. Earth, 23, 63-75, 1975.

Levitt, D. A. and D. A. Sandwell, Lithospheric bending at subduction zones based on depth soundings and satellite gravity, J. Geophys. Res., 100, 379-400, 1995.

Ludwig, W. J. and R. E. Houtz, Isopach map of sediments in the Pacific ocean basins and marginal sea basins, in The American association of petroleum Geologists, Tulsa, Oklahoma, 1979.

McAdoo, D. C., J. G. Caldwell, and D. L. Turcotte, On the elastic-perfectly plastic bending of the lithosphere under generalized loading with application to the Kuril trench, Geophys. J. R. astr. Soc., 54, 11-26, 1978.

Mizoue, M., Some remarks on the characteristics of subcrustal earthquake activities, Proceedings of Earthquake Prediction Research Symposium, pp. 97-105, 1977 (in Japanese with English abstract).

Mizoue, M., M. Nakamura, N. Seto, Y. Ishiketa, and T. Yokota, Threelayered distribution of microearthquakes in relation to focal mechanism variation in the Kii peninsula, southwestern Honshu, Japan, Bull. Earthquake Res. Inst., 58, 287-310, 1983.

Mueller, S. and R. J. Phillips, On the relaiability of lithospheric constraints derived from models Outer-Rise flexure, Geophys. J. Int., 123, 887-902, 1995.

Nakamura, Y. and T. Shibutani, Three-dimensional shear wave velocity structure in the upper mantle beneath the Philippine Sea region, Earth Planets Space, 50, 939-952, 1998.

Nemoto, K., R. Ishii, R. Daigo, and T. Asanuma, Sediment distribution of the Philippine Sea, in Geology and Geophysics of the Philippine Sea (Japan-Russia-China monograph), pp. 235-240, edited by H. Tokuyama, S. Shchka, N. Isezaki, S. Vysotskiy, R. Kulinich, B. Karp, E. Lelikov, K Fujioka, and G. Liu, 406 pp., Terrapub, Tokyo, 1995.

Nishizawa, A. and K. Suyehiro, Crustal structure across the Kuril Trench off southeastern Hokkaido by airgun-OBS profiling, Geophys. J. R. astr Soc., 86, 371-397, 1986.

Oda, H. and N. Senna, Regional variation in surface wave group velocities in the Philippine Sea, Tectonophys., 233, 265-277, 1994.

Okino, K., Y. Shimakawa, and S. Nagaoka, Evolution of the Shikoku Basin, J. Geomag. Geoelectr., 46, 463-479, 1994.

Sadeghi, H., A new ray tracing technique and its application to the seismic tomography of western Japan to eastern China region, Ph.D. Thesis, Kyushu University, 162 pp., 1999.

Sato, T. and M. Matsu'ura, A kinematic model for evolution of island arctrench systems, Geophys. J. Int., 114, 512-530, 1993.

Seekins, L. C. and T.-L. Teng, Lateral variations in the structure of the Philippine Sea plate, J. Geophys. Res., 82, 317-324, 1977.

Seno, T. and S. Maruyama, Paleogeographic reconstruction and origin of the Philippine Sea, Tectonophys., 102, 53-84, 1984.

Seno, T., S. Stein, and A. E. Gripp, A model for the motion of the Philippine Sea plate consistent with NUVEL-1 and geological data, J. Geophys Res., 98, 17941-17948, 1993.

Shih, T. C., Magnetic lineations in the Shikoku Basin, Initial Reports of the Deep Sea Drilling Project, 58, pp. 783-788, U.S. Government Printing Office, Washington, D.C., 1980.

Shiono, K., Seismicity of the SW Japan arc-Subduction of the young Shikoku Basin, Modern Geology, 12, 449-464, 1988.

Shiono, K. and N. Sugi, Life of oceanic plate: cooling time and assimilation time, Tectonophys., 112, 35-50, 1985.

Tanimoto, T., Bending of spherical lithosphere-axisymmetric case, Geophys. J. Int., 129, 305-310, 1997.

Tanimoto, T., State of stress within a bending spherical shell and its implications for subducting lithosphere, Geophys. J. Int., 134, 199-206, 1998.

Tomoda, Y., K. Ozawa, and J. Segawa, Measurement of gravity and magnetic field on board a crusing vessel, Bull. Ocean Res. Inst. Univ. of Tokyo, $\mathbf{3}$ $1-170,1968$.

Watts, A. B. and M. Talwani, Gravity anomalies seaward of deep-sea trenches and their tectonic implications, Geophys. J. R. astr. Soc., 36, 57-90, 1974.

White, S. M., H. Chamely, D. Curtis, G. de V. Klein, A. Mizuno, and D. M. Fountain, Sediment synthesis: Deep Sea Drilling Project Leg 58, Philippine Sea, in Reports of the Deep Sea Drilling Project, 58, pp. 963 1000, edited by G. de V. Klein, K. Kobayashi et al., Washington, 1980.

S. Yoshioka (e-mail: yoshioka@geo.kyushu-u.ac.jp) and Y. Ito 